\title{
The Comparison of Myocardial Dysfunction in Three Forms of Experimental Septic Shock
}

\author{
KEITH J. PEEVY, TIM REED, STEPHEN A. CHARTRAND, RICHARD D. OLSON, AND \\ ROBERT C. BOERTH \\ Departments of Pediatrics and Pharmacology, University of South Alabama, College of Medicine, \\ Mobile, Alabama 36617
}

\begin{abstract}
A rabbit model of septic shock was used to determine if 1) myocardial dysfunction is a common component of shock due to diverse neonatal pathogens, and 2) prostaglandins modulate septic myocardial dysfunction. The infusion of heat-killed Escherichia coli (group I), Haemophilus influenzae (group II), or Staphylococcus epidermidis (group III) produced significant decreases in the first derivative of left ventricular pressure with respect to time $(p<0.05)$. Each organism also produced significant changes in mean arterial pressure, cardiac output, and heart rate, while pulmonary artery pressure was altered in groups I and III. Saline-infused control animals (group IV) exhibited no significant changes in any hemodynamic variable. Blood gas variables were not significantly changed in any group. These cardiovascular changes appeared dependent on arachidonic acid metabolism since indomethacin pretreatment prevented the cardiovascular changes induced by bacterial infusion. These results suggest that septic myocardial dysfunction is a common component of gram-negative and gram-positive septic shock, and that myocardial dysfunction is modulated by prostaglandin products. (Pediatr Res 20: 1240-1242, 1986)
\end{abstract}

\section{Abbreviations}

GBS, group B streptococcus

PAP, pulmonary artery pressure

$\mathrm{LVdP} / \mathrm{dt}$, the first derivative of left ventricular pressure with respect to time

MAP, mean arterial pressure

HR, heart rate

$\mathrm{CO}$, cardiac output

EC, Escherichia coli

HI, Haemophilus influenzae

$\mathrm{SE}$, Staphylococcus epidermidis

IND, indomethacin

LVEDP, left ventricular end diastolic pressure

PG, prostaglandin

The pathogenesis of septic shock is poorly understood. Although hypotension, hypoxia, acidosis, and pulmonary hypertension appear to be common pathophysiologic events in septic shock, the mechanisms through which bacterial products act to precipitate these untoward events remain unclear. Clinical studies of septic adult and pediatric patients have suggested primary

Received February 13, 1986; accepted July 9, 1986.

Reprint requests Dr. Keith J. Peevy, Department of Pediatrics, University of South Alabama, 2451 Fillingim Street, Mobile, AL 36617.

This work was funded by a grant from the Alabama Chapter American Heart Association and by NIH Grant HL28711. myocardial dysfunction as a contributor to the evolution of shock $(1,2)$. In addition, depressed myocardial function has been demonstrated in a number of in vivo and in vitro studies using gram-negative organisms or endotoxin (3-5). Endogenous agents, primarily arachidonic acid metabolites, have been implicated as modulators of endotoxin-induced myocardial depression $(1,6)$.

In a previous study, we demonstrated myocardial dysfunction in response to experimental gram-positive septic shock (7). In our study, the infusion of GBS, caused a rapid decline in left ventricular $\mathrm{dP} / \mathrm{dt}$ that was independent of decreases in preload, increases in afterload, or changes in HR. The fall in left ventricular $\mathrm{dP} / \mathrm{dt}$ was prevented by prior administration of IND, suggesting a role for prostanoids in the modulation of GBS-induced myocardial dysfunction.

It appears likely that septic myocardial dysfunction is not unique to a particular organism, but is a common pathophysiologic response to many infectious agents. The purposes of this study were 1) to determine if acute myocardial dysfunction is produced by neonatal pathogens other than GBS and if so 2) is the myocardial dysfunction induced by these pathogens inhibited by the prior administration of IND.

\section{MATERIALS AND METHODS}

Animal preparation. Adult New Zealand White rabbits received pentobarbital anesthesia ( $30 \mathrm{mg} / \mathrm{kg}$ intravenous) and were placed on a small animal ventilator after tracheostomy. A midline sternotomy was performed, and catheters were inserted into the main pulmonary artery and left ventricle for measurement of PAP, the LVdP/dt, and LVEDP. Femoral arterial and venous catheters were placed for measurement of MAP, HR, arterial blood gases, and administration of bacteria. A $5.0 \mathrm{~mm}$ Statham flow probe attached to a Zepada flow meter was placed on the ascending aorta for measurement of $\mathrm{CO}$. All hemodynamic variables were recorded on a model R411 Beckman chart recorder. After surgery, animals were stabilized for $30 \mathrm{~min}$. Arterial blood gases were measured every $15 \mathrm{~min}$ and ventilation adjusted to maintain an alkalotic, hyperventilated state $(\mathrm{pH} \geq 7.5)$ so that anticipated bacterial induced decreases in $\mathrm{pH}$ would not cause severe acidosis and affect MAP, CO, and LVdP/dt.

Bacterial preparation. Clinical isolates of EC, $\mathrm{HI}$ (nontypable), or SE were used in all experiments. Bacteria were grown overnight on blood agar, suspended in sterile, nonpyrogenic saline to a quantified density of $10^{11}$ colony-forming units per milliliter, and then killed by heating to $100^{\circ} \mathrm{C}$ for $15 \mathrm{~min}$.

Experimental sequence. Part I. Four experimental groups were used. Animals receiving bacterial suspensions were given heat killed EC (group I), HI (group II), or SE (group III) by constant infusion $\left(0.3\right.$ to $0.5 \mathrm{ml} / \mathrm{kg} / \mathrm{min}$ of $10^{11}$ organisms $\left./ \mathrm{ml}\right)$ to a total dose of $10^{12}$ organisms per $\mathrm{kg}$. Values for hemodynamic variables and arterial blood gases were obtained immediately before (base- 
line) and $30 \mathrm{~min}$ after the beginning of the infusion. Control animals (group IV) received a volume of sterile saline equal to the volume of heat-killed organisms used in the other three groups and had each variable assessed at before and $30 \mathrm{~min}$ after the saline infusion.

Part II. Four animals randomly selected to receive either EC, $\mathrm{HI}$, or SE were pretreated with IND $(4 \mathrm{mg} / \mathrm{kg})$, and then infused with the bacterial suspension as described in part I. Two of the four animals received SE, one received $\mathrm{EC}$ and one received $\mathrm{HI}$. Values for hemodynamic variables and blood gases were obtained immediately before IND, $15 \mathrm{~min}$ after the IND bolus, and $30 \mathrm{~min}$ from the beginning of the bacterial infusion.

Statistical analyses were performed on each variable between groups (unpaired data) using one-way analysis of variance then Duncan's new multiple range test and within groups (paired data) using the paired $t$ test, or randomized block design analysis of variance then Duncan's new multiple range test. A $p$ value of $<0.05$ was considered significant for all comparisons.

\section{RESULTS}

Part I. Table 1 shows the values for $\mathrm{LVdP} / \mathrm{dt}, \mathrm{MAP}, \mathrm{PAP}, \%$ change in $\mathrm{CO}$ and $\mathrm{HR}$ before and 30 minutes after beginning the bacterial infusion in the four groups. Animals in groups I (EC), II (HI), and III (SE) had significant falls in LVdP/dt and MAP $(p<0.05)$, while the control group did not elicit a significant change in either variable (group IV). Animals in groups I (EC) and III (SE) showed significant rises in PAP $(p<0.05)$, while group II (HI) and group IV (control) did not. Infusion with $\mathrm{EC}, \mathrm{HI}$, and SE bacterial suspensions caused a significant fall in both $\mathrm{CO}$ and HR. In contrast, the control animals did not have significantly altered $\mathrm{CO}$ or HR compared to baseline presaline infusion values. In no group was LVEDP or systemic vascular resistance significantly altered (data not shown).

Table 2 lists values for $\mathrm{pH}$ and $\mathrm{pO}_{2}$ before (baseline) and at 30 min following the beginning of infusion with either the bacterial suspensions (groups I-III) or saline (group IV). Each group had a baseline $\mathrm{pH}$ of 7.5 or greater and no group had a statistically significant fall in $\mathrm{pH}$, although group III (SE) had a mean decline of $0.11 \mathrm{pH}$ units (7.52 to 7.41). Mean values for $\mathrm{pO}_{2} 30$ min after beginning the infusion in the four groups were not significantly lower than the baseline preinfusion values in any group.

Part II. Table 3 shows the effects of bacterial suspensions infusion on MAP, LVdP/dt PAP, CO, and $\mathrm{HR}$ in animals pretreated with IND. IND pretreatment abolished the expected fall in CO, MAP, and $\mathrm{LVdP} / \mathrm{dt}$ and rise in PAP associated with the bacterial infusion. HR and LVEDP were not significantly altered in animals in part II. Thus, IND protected against the bacterial induced alterations in the cardiovascular hemodynamic parameters.

\section{DISCUSSION}

Our study demonstrates myocardial dysfunction in response to three diverse bacterial pathogens. These results are similar to those previously obtained in the same model using heat-killed GBS (7), and suggests that myocardial dysfunction is a common component of septic shock induced by various types of bacteria. Defining the mechanism for a single pathophysiological alteration is difficult in in vivo studies. In our model $\mathrm{LVdP} / \mathrm{dt}$ could have been altered by changes in preload (LVEDP), HR, afterload, and the intrinsic contractile state of the heart $(8,9)$. In the present study only HR was significantly decreased in any group, and by a maximum of only $16 \%$ (group I). Thus, it would appear that the decrease in $\mathrm{LVdP} / \mathrm{dt}$ primarily reflects alterations in the contractile state of the myocardium.

In part II of this study, pretreatment with IND prevented the myocardial dysfunction observed in part I. These results are similar to those seen in our previous study of GBS-induced myocardial dysfunction and add further evidence that septic myocardial dysfunction is modulated through prostanoid production (7). Prostanoid alteration of myocardial function could

Table 2. Baseline and postinfusion arterial blood gas values (mean $\pm S E$ )

\begin{tabular}{|c|c|c|c|}
\hline Group* & $\mathrm{pH}$ & $\mathrm{pO}_{2}$ & $\mathrm{pCO}_{2}$ \\
\hline \multicolumn{4}{|l|}{$\mathrm{I}(n=4)$} \\
\hline Baseline & $7.60 \pm 0.01$ & $76 \pm 9$ & $16 \pm 1$ \\
\hline $\mathrm{EC}$ & $7.56 \pm 0.03$ & $59 \pm 12$ & $15 \pm 3$ \\
\hline \multicolumn{4}{|l|}{ II $(n=4)$} \\
\hline Baseline & $7.54 \pm 0.04$ & $54 \pm 2$ & $17 \pm 2$ \\
\hline $\mathrm{HI}$ & $7.51 \pm 0.05$ & $53 \pm 9$ & $12 \pm 6$ \\
\hline \multicolumn{4}{|l|}{ III $(n=6)$} \\
\hline Baseline & $7.52 \pm 0.02$ & $63 \pm 7$ & $18 \pm 2$ \\
\hline $\mathrm{SE}$ & $7.41 \pm 0.05$ & $48 \pm 10$ & $22 \pm 4$ \\
\hline \multicolumn{4}{|l|}{ IV } \\
\hline Baseline & $7.62 \pm 0.04$ & $77 \pm 11$ & $23 \pm 6$ \\
\hline Saline & $7.59 \pm 0.03$ & $76 \pm 12$ & $24 \pm 6$ \\
\hline
\end{tabular}

* No significant differences were noted.

Table 1. Baseline and postinfusion values for selected hemodynamic variables (mean \pm SE)

\begin{tabular}{|c|c|c|c|c|c|c|}
\hline Group & $\mathrm{MAP}(\mathrm{mm} \mathrm{Hg})$ & $\begin{array}{c}\mathrm{LVdP} / \mathrm{dt} \\
(\mathrm{mm} \mathrm{Hg} / \mathrm{s})\end{array}$ & $\mathrm{PAP}(\mathrm{mm} \mathrm{Hg})$ & $\begin{array}{c}\mathrm{CO}(\% \text { of } \\
\text { change from } \\
\text { baseline) }\end{array}$ & LVEDP & HR (beats/min) \\
\hline \multicolumn{7}{|l|}{$I(n=4)$} \\
\hline Baseline & $90 \pm 6$ & $7373 \pm 1700$ & $18.3 \pm 1.3$ & & $1.5 \pm 0.6$ & $304 \pm 11$ \\
\hline $\mathrm{EC}$ & $52 \pm 5^{*}$ & $2439 \pm 932^{*}$ & $26 \pm 0.6^{*}$ & $52 \pm 12^{*}$ & $1.3 \pm 0.5$ & $253 \pm 12^{*}$ \\
\hline \multicolumn{7}{|l|}{ II $(n=4)$} \\
\hline Baseline & $91 \pm 10$ & $5506 \pm 1082$ & $15.3 \pm 4$ & & $2.5 \pm 1.7$ & $280 \pm 9$ \\
\hline $\mathrm{HI}$ & $57 \pm 11^{*}$ & $2931 \pm 946^{*}$ & $17.8 \pm 4.6$ & $36 \pm 8^{*}$ & $1.0 \pm 0.7$ & $265 \pm 11^{*}$ \\
\hline \multicolumn{7}{|l|}{ III $(n=6)$} \\
\hline Baseline & $83 \pm 4$ & $5539 \pm 334$ & $14.3 \pm 2.4$ & & $5.1 \pm 1.7$ & $314 \pm 9$ \\
\hline SE & $45 \pm 4^{*}$ & $2234 \pm 429^{*}$ & $22.8 \pm 2.6^{*}$ & $60 \pm 12^{*}$ & $2.8 \pm 0.9$ & $270 \pm 20^{*}$ \\
\hline \multicolumn{7}{|l|}{ IV $(n=4)$} \\
\hline Baseline & $90 \pm 5$ & $5862 \pm 605$ & $17.3 \pm 0.6$ & & $1.5 \pm 0.5$ & $242 \pm 10$ \\
\hline Saline & $90 \pm 4$ & $5952 \pm 428^{*}$ & $18.5 \pm 1.3$ & $5 \pm 3$ & $3.0 \pm 1.2$ & $263 \pm 5$ \\
\hline
\end{tabular}

\footnotetext{
* Significant difference from base $(p<0.05)$
} 
Table 3. Hemodynamic values assessed at baseline and 30 min after infusion of bacteria in rabbits pretreated with IND $($ mean $\pm S E)$

\begin{tabular}{|c|c|c|c|c|c|c|}
\hline Group & $\mathrm{MAP}(\mathrm{mm} \mathrm{Hg})$ & $\mathrm{PAP}(\mathrm{mm} \mathrm{Hg})$ & $\mathrm{LVdP} / \mathrm{dt}$ & $\begin{array}{c}\mathrm{CO}(\% \text { of } \\
\text { change from } \\
\text { baseline })\end{array}$ & LVEDP & HR (beats/min) \\
\hline Baseline & $91 \pm 9$ & $18.5 \pm 1.0$ & $6494 \pm 1333$ & & $3.0 \pm 0.9$ & $299 \pm 10$ \\
\hline IND & $86 \pm 6$ & $18.3 \pm 1.4$ & $5360 \pm 812$ & $2 \pm 5$ & $3.8 \pm 0.5$ & $303 \pm 9$ \\
\hline Bacteria & $75 \pm 4^{*}$ & $20.0 \pm 0.9$ & $5511 \pm 894$ & $-4 \pm 12$ & $1.5 \pm 1.5$ & $303 \pm 17$ \\
\hline
\end{tabular}

* Denotes significant difference between baseline and bacteria. No statistically significant differences were found between baseline and IND or between IND and bacteria.

be produced through changes in coronary perfusion $(10,11)$, by production of right ventricular afterload and secondary left ventricular dysfunction (12), via a direct effect of prostanoids on myocardial contractile function $(13,14)$, or secondary to increased free radical production via oxygen radical production during the reduction of $\mathrm{PGG}_{2}$ to $\mathrm{PGH}_{2}(15-17)$.

In summary, we have shown that myocardial dysfunction occurs in a rabbit model of septic shock caused by EC, HI, and $\mathrm{SE}$, and can be prevented by the PG synthetase inhibitor, IND. These data support the concept that septic myocardial dysfunction is a common component of both gram-negative and grampositive septic shock and that myocardial dysfunction is modulated by $\mathrm{PG}$ products. Further work is needed to elucidate the mechanism(s) for septic myocardial dysfunction.

\section{REFERENCES}

1. Parrillo $\mathbf{J} 1985$ Cardiovascular dysfunction in septic shock: new insights into a deadly disease. Int J Cardiol 7:314-321

2. Hess M. Hastillo A. Greenfield L 1981 Spectrum of cardiovascular function during gram-negative sepsis. Prog Cardiovasc Dis 23:279-298

3. Archer L. Benjamin B. Beller-Todd B. Brackett D. Wilson M, Hinshaw L 1982 Does $\mathrm{LD}_{100} E$. coli shock cause myocardial failure? Circ Shock 9:7-16

4. Parker J. Adams H 1979 Myocardial effects of endotoxin shock: characterization of an isolated heart muscle model. Adv Shock Res 2:163-175

5. Parker J 1983 Contractile function of heart muscle isolated from endotoxinshocked guinea pigs and rats. Adv Shock Res 9:133-145

6. Carli A. Auclair M. Vernivumen C 1983 Indomethacin suppresses early cardiodepressant factor released by endotoxin in the rat: possible involvement of a prostacyclin related material. Adv Shock Res 10:161-171

7. Peevy K, Chartrand S, Wiseman H, Boerth R, Olson R 1985 Myocardial dysfunction in group B streptococcal shock. Pediatr Res 19:511-513

8. Neill W 1976 Regulation of cardiac output. In: Levin HJ (ed) Pediatric Clinical Cardiovascular Physiology. Grune and Stratton New York, pp 121-142

9. Skelton C, Sonnenblick E 1976 Physiology of cardiac muscle. In: Levin HJ (ed) Clinical Cardiovascular Physiology. Grune and Stratton, New York, pp 57-120

10. Gerritsen M, Cheli C 1983 Arachidonic acid and prostaglandin endoperoxide metabolism in isolated rabbit and coronary microvessels and isolated and cultivated coronary microvessel endothelial cells. J Clin Invest 72:16581671

11. Posner P, Lambert C 1982 Study of prostaglandin $E_{1}$ and $F_{2} a$ on isolated mammalian cardiac tissue. Pharmacology 25:26-3212

12. Ghignone M, Girling L, Prewitt R 1984 Effect of increased pulmonary vascular resistance on right ventricular systolic performance in dogs. Am J Physiol 246:H339-H343

13. Fozzard H 1977 Heart: excitation-contraction coupling. Ann Rev Physiol 39:201-220

14. Kecskemeti V, Keleman K, Knoll J 1976 Dose-dependent effect of prostaglandins on cardiac transmembrane potential. Acta Biol Med Germ 35:11731174

15. Kuehl FA, Ham EA, Egan RN, Dougherty HW, Bonney RJ, Humes JL 1982 Studies on a destructive oxidant released in the enzymatic reduction of prostaglandin $G_{2}$ and other hydroporoxy acids. In: Autor A (ed) Pathology of Oxygen. Academic Press, New York, pp 175-188

16. Egan RN, Paxton J, Kuehl FA 1976 Mechanisms for irreversible self-deactivation of prostaglandin synthetase. J Biol Chem 251:7329-7335

17. Egan RN, Gale PH, Kaehl FA 1979 Reduction of hydroperoxide in the prostaglandin biosynthetic pathway by a microsomal peroxidase. J Biol Chem 254:3295-3302 